\title{
PERCEPÇÃO SENSORIAL, DESIGN UNIVERSAL E USABILIDADE SOB A ÓTICA DA PRÁTICA PROJETUAL CENTRADA NO USUÁRIO
}

\author{
LIVRAMENTO DA SILVA, Renato Fonseca (1); \\ COSTA, Angelina Dias Leão (2) \\ (1) Universidade Federal da Paraíba, Mestrado \\ e-mail:fonsilva3@hotmail.com \\ (2) Universidade Federal da Paraíba, Doutorado \\ e-mail: angelinadlcosta@yahoo.com.br
}

\begin{abstract}
RESUMO
Este artigo apresenta uma revisão bibliográfica de quatro temas importantes para reflexão e troca de saberes entre arquitetos e designers durante o desenvolvimento de ambientes construídos (na escala do edifício) e produtos (tecnologias assistivas), baseados em uma prática projetual centrada no usuário, princípios de usabilidade, sistemas sensoriais e desenho universal. Fomentar essa discussão, em busca de uma linguagem comum (ou pelo menos clara entre as áreas de conhecimento em questão) pode contribuir para ambientes e produtos mais acessíveis, capazes de comunicar melhor seus atributos de forma segura e equitativa, e porque não dizer, com uma dimensão mais humana.
\end{abstract}

Palavras chave: projeto centrado no usuário; percepção sensorial; desenho universal e usabilidade.

\begin{abstract}
This article presents a bibliographical review of four important themes for the reflection and exchange of knowledge between architects and designers during the development of built environments and in the area of activities (assistive technologies), based on a project practice centered not user groups, principles of Usability, sensory systems and universal design. Encouraging this discussion, in search of a common (or at least clear among the areas of knowledge in question) can contribute to more accessible environments and products, able to communicate their attributes in a safe and equitable way, and why not say, with a more human dimension.
\end{abstract}

Keywords: user-centered design; sensory perception; universal design and usability.

\section{INTRODUÇÃO}

O ser humano, no decorrer de sua história, vem alterando de forma significativa o meio natural para satisfação de suas necessidades. Ao abordar a estruturação do ambiente na escala urbana (GEHL, 2013), coloca que "por décadas a dimensão humana tem sido um tópico do planejamento urbano esquecido e tratado a esmo". (GEHL 2013, p. 3) Assim, as cidades vêm assumindo uma configuração pautada no atendimento das necessidades de um modelo de homem ideal, distanciando-se da realidade composta por sociedades predominantemente caracterizadas pela diversidade humana. Sendo assim, a arquitetura e o design possuem importante papel para a interpretação das 


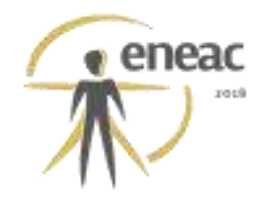

a arquitetura dos últimos trinta anos, em vez de proporcionar uma experiência plástica e espacial embasada na experiência humana, tem adotado a estratégia psicológica da publicidade e da persuasão instantânea; as edificações se tornaram produtos visuais desconectados da profundidade existencial e da sinceridade. (PALLASMAA, 2011. p.29).

Nesta perspectiva, o desenvolvimento de novos ambientes, assim como, dos produtos e serviços que os integram às reais necessidades das pessoas, e que com eles interagem ao longo de suas vidas, carece de uma abordagem de projeto orientada para os conceitos de acessibilidade, uma vez que, o processo de desenvolvimento do ambiente construído, assim como de produtos, é de natureza complexa, envolvendo diversos fatores a serem compreendidos.

Por outro lado, o termo "acessibilidade" é abrangente e comporta múltiplos conceitos e definições - alguns assumem uma abordagem pontual, focada na superação das barreiras físicas que fazem parte dos ambientes e uso de produtos. Existem ainda definições amplas, baseadas em interpretações sobre as interações que se constroem na complexidade que caracteriza o convívio social.

No Brasil a ABNT NBR 9050 de 2015, define acessibilidade como sendo a

possibilidade e condição de alcance, percepção e entendimento para utilização, com segurança e autonomia, de espaços, mobiliários, equipamentos urbanos, edificações, transportes, informação e comunicação, inclusive seus sistemas e tecnologias, bem como outros serviços e instalações abertos ao público, de uso público ou privado de uso coletivo, tanto na zona urbana como na rural, por pessoa com deficiência ou mobilidade reduzida. (ABNT NBR 9050, 2015, p.2).

Para Dischinger (2000), a acessibilidade não é apenas conectada a fatores físicos, como distância, locação e conforto, mas também a aspectos sociais, econômicos e culturais, que são determinantes na caracterização dos desafios a serem enfrentados por populações distintas e estão situados na origem dos problemas de acessibilidade.

Já Alvarez (2003) coloca que,

a acessibilidade espacial vai mais longe do desenho propriamente dito, é um compromisso social, com a defesa dos direitos das pessoas que devem ser incorporados aos fundamentos pelos que projetam e planejam qualquer atuação civil. (ALVAREZ, 2003, p. 4).

Em relação acessibilidade físico espacial, não se trata apenas da "possibilidade de atingir um lugar desejado, mas também de compreender a função, a organização e as relações espaciais, bem como de participação das atividades nele existentes". (DISCHINGER, BINS ELY e PIARDI, 2012, p.28).

No entanto, à medida que ocorre o distanciamento em relação à reflexão sobre conceitos de acessibilidade, sobretudo de sua importância nos processos de concepção (projeto) dos ambientes construídos, assim como, produtos e serviços que os integram, estamos de certa forma negligenciando a possibilidade de ampliar o uso e entendimento dos espaços de forma segura e amigável para um maior número de pessoas. Contudo, para projetar para a complexidade que caracteriza as sociedades contemporâneas torna-se importante,

compreender os aspectos sensoriais, emocionais, econômicos e socioculturais que definem as nossas escolhas é de fundamental importância para arquitetos, designers e empresas, uma vez que nos possibilita ampliar as experiências de uso e consumo e geram precedentes para a criação de produtos, ambientes e projetos de arquitetura mais favoráveis aos indivíduos. (PAIVA, 2018, p.12). 


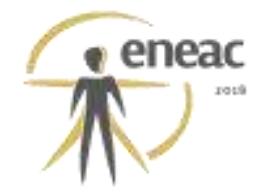

Sendo assim, a arquitetura e o design possuem importante papel para a interpretação das ações e manifestações da diversidade humana na estruturação de propostas para melhoria do mundo material, principalmente para minimizar as dificuldades decorrentes da incompatibilidade entre as características do meio construído e as necessidades das pessoas que nele vivem.

a arquitetura contemporânea tem levado os arquitetos a resolverem problemas habitacionais de forma e função, sem considerar os aspectos sociais e psicológicos em termos de conforto humano e sem entender a arquitetura como conjunto de interações e inter-relações dinâmicas dos sentidos humanos. (CASTILHO,2009. p.33).

Embora tenham ocorrido significativos avanços em ações no sentido de trazer para o processo de projetação de ambientes e produtos, informações sobre questões físicas (materiais, dimensões, etc.), por outro lado trabalhos relacionados aos processos cognitivos durante a interação e uso dos ambientes construídos e produtos que os integram é pertinente no campo da arquitetura, assim como do design, esforços para ampliar o desenvolvimento de trabalhos aplicados com este propósito. A este respeito, e mais especificamente em relação a emoção das pessoas ao interagirem com produtos, Niemeyer (2008) coloca que:

- conhecimento sobre os processos perceptivos que enriquecerão a interação do ser humano com o produto, ampliando o espaço sensorial da interação. Enquanto processos visuais básicos têm sido extensamente estudados sob condições controladas do laboratório, pouco ainda se sabe sobre outras modalidades do sentido (indispensável o conhecimento das percepções organolépticas, por meio de tato, audição, cheiro e gosto) e sobre como as pessoas percebem os produtos e que significado atribuem a ele. (NIEMEYER 2008, p.59).

Assim, o presente trabalho traz uma revisão de temas que norteiam uma pesquisa de doutorado em andamento na Universidade Federal da Paraíba/PPGAU, que pretende refletir sobre pontos em comum entre os temas: percepção sensorial, desenho universal e usabilidade, aplicados ao conceito de projeto centrado no usuário com intuito de auxiliar o desenvolvimento de Tecnologias Assistivas (TA) voltadas para o ambiente construído e especificamente na escala do edifício.

\section{OS CONCEITOS EM ESTUDO}

\subsection{Como os sentidos ajudam a perceber o ambiente}

Natureza e ação antrópicas proporciona cenários nos quais se desenvolvem todas as relações e práticas humanas, ou seja, delineiam uma sociedade físico-espacial em constante transformação. Entende-se, compartilhando a ideia de Santos (1985), que o espaço é constituído não apenas por objetos geográficos naturais e artificiais, mas também por processos sociais que lhe dão vida. É a partir da percepção e da interpretação do espaço assim constituído que as pessoas interagem com ele, reconhecendo os elementos que o compõem, tanto sua materialidade quanto os múltiplos significados que lhes são atribuídos.

Contudo, para perceber algo e, por consequência, estabelecer uma interação com o meio, é fator primordial a precedência de uma sensação que se refere ao "processo biológico de captação e transmissão de energia ambiental por meio das células nervosas dos órgãos sensoriais". (IIDA, 2005, p.258).

Sendo "a percepção aquela que se dá em consequência ao processamento do estímulo 


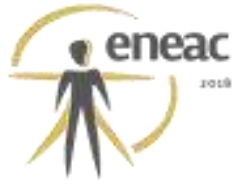

sensorial, dando-Ihe um significado" (IIDA,2005, p. 258), o autor coloca que os estímulos recebidos são organizados e integrados pelo interlocutor, que utiliza informações já armazenadas na sua memória sobre objetos e meio ambiente para transformar sensações em significados, relações e julgamento.

Sobre esse tema, "a percepção não é uma cópia autêntica do mundo exterior; o mundo exterior subjetivamente vivido é percebido por um processo sensorial e modulado por um processo puramente subjetivo" (GRANDEJEAN,1998, p. 199). Para o autor, "a percepção nos fornece, como regra geral, informações necessárias para a reação adequada ao mundo exterior" (GRANDEJEAN, 1998, p.200).

Nesse sentido, as sensações acionam a interpretação, momento responsável por organizar e dar significado aos estímulos recebidos. Em síntese, constituída por sensação e interpretação, pode-se considerar que a percepção humana é a resposta dada aos estímulos captados por receptores sensoriais que coletam as informações existentes no ambiente; e que se espera

uma experiência dotada de significação, isto é, o percebido é dotado de sentido e tem sentido em nossa história de vida, fazendo parte de nosso mundo e de nossas vivências; [...] é assim uma relação do sujeito com o mundo exterior [que] dá sentido ao percebido e ao percebedor, e um não existe sem o outro; o mundo percebido é qualitativo, significativo, estruturado e estamos nele como sujeitos ativos isto é, damos às coisas percebidas novos sentidos e novos valores, pois as coisas fazem parte de nossas vidas e interagimos com o mundo. (CHAUÍ, 1995. p. 122-123).

No processo perceptivo Tuan (1980) insere a participação da cultura, enfatizando que as infinitas possibilidades de perceber e avaliar o meio ambiente são influenciadas por aspectos culturais determinantes da visão de mundo, dos indivíduos e dos grupos humanos. Assim, os homens percebem e interpretam a realidade de forma tão variada quanto variados são os modos de vida. Nessa direção convergem os argumentos de Carlin (2004), quando considera que a percepção ambiental leva o indivíduo a reconhecer o ambiente construído como espaço vivencial.

Através dos sentidos, o espaço arquitetônico é percebido e transformado em espaço simbólico, o espaço pensado e representado na mente (imagem mental). A interpretação do espaço simbólico, através da consciência e do pensamento (onde estão incluídas todas as características do indivíduo), levará a uma tomada de decisão, ao comportamento, transformando o espaço arquitetônico em espaço vivencial. (CARLIN, 2004, p. 50).

Ao tratar os sentidos e a comunicação, GEHL (2010) coloca que em grandes distâncias, recolhemos uma grande quantidade de informações sobre o ambiente, mas a intensidade das informações tendem a se acentuar e trazer aspectos emocionais mais significativos quando estamos em distâncias curtas, isso ocorre porque os sentidos que estão incluídas todas as características do indivíduo operam nesta situação são mais ligados às nossas emoções como o olfato, tato e a capacidade de reconhecer sinais de temperatura.

Essa perspectiva comporta a ideia de que a percepção do mundo exterior é acionada por informações captadas do ambiente que para Gibson (1966) partem dos cinco sistemas sensoriais relacionados. O primeiro Sistema é o Básico de Orientação que é responsável pelo equilíbrio do corpo e orientação respondendo às forças de gravidade e aceleração, o segundo é o Háptico, relacionado ao tato passivo e ativo, e pela distinção de temperaturas e movimento próprio, respondendo aos receptores de temperatura da pele, às deformações de tecidos e músculos, e a configuração de juntas; o Sistema Visual é responsável pela percepção instantânea do ambiente, trazendo informações relacionadas as profundidades, distâncias, configuração formal e as dinâmicas que ocorrem nos espaços; e o Auditivo por escutar e identificar a direção dos sons, detectar a natureza do som e a eventos vibratórios. 


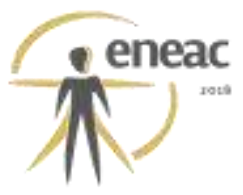

Já o Sistema de Olfato/Paladar é responsável por identificar os odores e paladar, respondendo a composição química do meio e de objetos ingeridos.

A teoria de percepção sensorial de Gibson (1966) é significativa pois colabora para o entendimento de como nossos sentidos funcionam como sistemas interligados para obter informações sobre o mundo. $O$ autor coloca também que as informações podem ser obtidas com qualquer um dos sistemas perceptivos sozinhos, ou por meio de qualquer combinação entre eles. O que traduz que um sentido não valida outro e não é necessário que um sentido adquira significado a partir de outro.

Sobre o tratamento das informações percebidas pelos sistemas sensoriais descritos por Gibson (1966) e Bins Ely (2004) diz que ele é baseado em atividades mentais, pelas quais representações são estruturadas a partir do conhecimento adquirido, dando significado aos elementos resultantes dessa análise perceptiva. Segundo a autora, existem basicamente dois resultados de tais atividades: um interno ao sistema cognitivo, que se relaciona ao processo de interpretação e utilização das informações, e outro associado ao resultado comportamental direto, ou seja, refere-se às decisões de ação.

Nos casos de redução ou falta de informação visual, condição extrema que gera grande desvantagem para as pessoas interagirem com os ambientes construídos e produtos,

\begin{abstract}
o sentimento de direção irá depender bem mais da estrutura propriocêntrica de referências do indivíduo (sentidos orientacionais e táteis) e das possibilidades de recognição de pontos de referência externos. Sons serão um dos mais importantes fornecedores de informação exteriorcêntrica, seguido pelo cheiro em um grau menor. (DISCHINGER, 2000, p. 87).
\end{abstract}

Nesta perspectiva, cabem esforços para a criação de recursos de projetação, que sejam capazes de contribuir com o incremento de informações para arquitetos e designers durante o desenvolvimento do ambiente construído e produtos diversos, sobretudo no sentido de trazer reflexões sobre a possibilidade de experimentar novos caminhos para materializar conceitos, requisitos e alternativas de propostas baseados nos conhecimentos dos sistemas sensoriais, articulados com os outros conceitos que são apresentados neste artigo. Partindo desta premissa, acredita-se que as possibilidades de respostas de projeto nas mais diversas escalas, podem ser ampliadas, contribuindo para que os ambientes e produtos comuniquem seus atributos de forma clara segura e equitativa, proporcionando cada vez mais um sentido de pertencimento e segurança das pessoas em relação ao seu convívio social, sobretudo as pessoas que se encontram em desvantagens.

\title{
2.2 Do Design Inclusivo ao Desenho Universal
}

As abordagens inclusiva e universal de projeto, traduzem um posicionamento crítico perante o desenvolvimento de ambientes, produtos e serviços. Colaborando assim, para a construção de uma sociedade mais democrática e sustentável.

"É possível conceber e produzir produtos, serviços ou ambientes adequados a esta diversidade humana" incluindo crianças, idosos, pessoas com deficiência, doentes ou feridos, ou "simplesmente pessoas colocadas em desvantagem pelas circunstâncias". (SIMÕES E BISPO, 2006, p. 8). Essa abordagem é denominada design inclusivo.

Através da prática do "Design Inclusivo" será possível a construção de cidades mais amigáveis para todos. $O$ argumento mais persuasivo para adotar o Design Inclusivo consiste no princípio ético que todos os indivíduos têm o mesmo direito fundamental de aceder e utilizar com segurança e conforto o ambiente edificado, bem como os produtos e serviços que nele estão integrados em todas as escalas. (SIMÕES E BISPO, 2006, p. 61)

Para Bispo (2006, p. 24) "o design inclusivo é uma abordagem de projeto que visa o desenvolvimento de soluções centradas na diversidade, procurando, assim, contribuir para 
uma sociedade mais justa, onde todas as pessoas têm direito a igualdade de oportunidades". Essa abordagem se assenta no reconhecimento da importância que o meio edificado, os bens de consumo e o acesso à informação neles contidas, têm no processo de interação das pessoas com o mundo material. Neste sentido, a indústria, quer seja ela da construção civil, de bens de consumo (produtos diversos), tem a responsabilidade de contribuir para que a produção atenda satisfatoriamente às reais necessidades das populações.

Em relação ao termo Desenho Universal, esse, naturalmente, tende a ampliar as potencialidades dos ambientes construídos e produtos, e esta abordagem de projeto colabora para melhorar a interação com ambientes, produtos e serviços para um maior número de pessoas possíveis de diferentes características, não se restringindo apenas a atender demandas de pessoas com restrições especificas.

\begin{abstract}
Perante os seus significados etimológicos, design universal e design inclusivo podem ser delineados como duas variantes diferentes, sendo o design universal responsável pela criação de produtos que possam ser utilizados, de modo equitativo, excluindo da sua utilização o menor número de pessoas possível, enquanto o design inclusivo passa pela criação de produtos para um público com características limitadoras, que necessita de equipamentos que atenuem limitações e permita maximizar a sua integração nas atividades diárias. (CRUZ, 2010, p.5).
\end{abstract}

Estes dois conceitos implicam em diferentes perspectivas sobre o processo de projeto e interessa-nos com maior intensidade o conceito de desenho universal desenvolvido pelo arquiteto estadunidense Ronald L. Mace, que foi a primeira pessoa a utilizar, divulgar e aplicar o termo nos anos de 1980 juntamente com sua equipe do The Center for Universal Design da North Carolina State University, EUA, difundindo os sete princípios do Desenho Universal: Uso equitativo, Flexibilidade no uso, Uso simples e intuitivo, Informação perceptível, Tolerância a erro, Baixo esforço físico, Tamanho e espaço para aproximação e uso. Este conjunto de princípios objetivou "sistematizar os conceitos de design universal para pesquisas técnicas e informação referencial, bem como para incorporação nas demais instituições de ensino". (CAMBIAGHI, 2007, p. 73).

Nessa perspectiva, Simões (2006) aponta semelhanças entre as diferentes abordagens e as concilia ao conceito de design universal formulado por Ronald Mace:

Numa sociedade democrática, a prática projetual deve incorporar uma atitude ética, de respeito pelos direitos humanos, e a criação de condições para o exercício, por todos, de uma cidadania plena em condições de igualdade de oportunidades. Partindo do princípio que as pessoas são diferentes e com diferentes capacidades, considera-se que não deverão ser as pessoas obrigadas a adaptar-se às exigências do meio ambiente, mas pelo contrário, que os produtos e os ambientes é que deverão corresponder às necessidades das pessoas. A participação dos diversos tipos de utilizadores na identificação dos problemas existentes, no desenvolvimento dos projetos e na avaliação das soluções propostas, é um fator importante para a obtenção de produtos e ambientes sustentáveis, de qualidade e um uso o mais abrangente possível. (SIMÕES 2006, p. 14).

Para Franco (2001),

o design universal é, acima de tudo, uma metodologia de trabalho que coloca em especial evidência uma atitude crítica face ao ato projetual a principal materialização deste conceito é um produto - bem ou serviço - que deve ser acessível ao maior número possível de clientes, independentemente de sua idade, situação financeira, nível cultural, capacidade física, entre outros. (FRANCO, 2001, p. 86). 


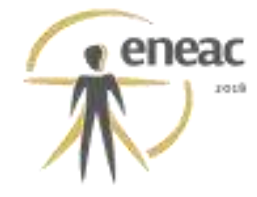

Cabe salientar que no Brasil, "poucos profissionais ou instituições de ensino têm adotado a arquitetura e o design inclusivo como eixo central de seus trabalhos". (CAMBIAGHI 2007, p. 80). Na opinião da autora, estes profissionais perdem a oportunidade de se beneficiar, entre outros aspectos, com a redução do tempo de elaboração do programa de necessidades dos produtos e serviços.

Contudo, a partir do entendimento de que o conceito de desenho universal está claramente fundamentado sob a ótica da diversidade humana, pode-se atribuir a ele o caráter de princípio básico para proporcionar o acesso ao maior número de pessoas de forma segura e confortável aos ambientes edificados e produtos e que os integram e por consequência prover acessibilidade.

\subsection{A Usabilidade como aspecto primordial do projeto}

O tema metodologia de projeto é relativamente recente na história das sociedades industriais, contudo, "a partir da década de 1950 e, principalmente ao longo da década de 1960, houve um grande esforço em diversas áreas projetuais para o desenvolvimento de métodos". (VAN DER LINDEN E LACERDA, 2012.p.89). Na "década de 1960, constatou-se o auge da metodologia projetual, quando os interesses anglo-saxão e teutônico se voltaram para esse campo, até então mantido em estado de tranquilidade bucólica" e este processo culminou com a "academização da metodologia, institucionalizada como disciplina universitária" (BOSIEPE,2012.p.90). Este fato, ocorreu principalmente em função da constatação dos partidários da nova disciplina que surgira, de um certo subdesenvolvimento e atraso da atividade projetual, quando comparada a outras áreas de conhecimento, como as técnico-científicas. Para 0 autor, neste contexto, fica evidente a necessidade de instrumentos confiáveis para uso dos projetistas, inclusive na Arquitetura e no Design.

Entretanto, as "metodologias da década de 1960 não deram ênfase especial para alguns aspectos hoje considerados imprescindíveis". Entre estes aspectos, destaca-se o "respeito a certas minorias populacionais, como as pessoas idosas e aquelas que possuem alguma deficiência“. (BONSIEPE, 2012.p.93). Já na década 1970, Jones (1976) apresenta em sua obra Design Methods um agrupamento de técnicas para auxiliar a condução de projetos, e reflexões em relação ao próprio processo de projeto. Após este fato, uma quantidade significativa de novos métodos surgiu, podemos citar entre tantas: Bonsiepe (1978); Löbach (1981); Munari (1981); Bomfim (1984), Schulmann (1994); Baxter (1998); Manzini e Verzzoli (2002), Santos (2006); Paht et al. (2008); Merino (2014). Este fato ocorre, principalmente em função dos constantes avanços dos produtos em termos de complexidade formal e construtiva nas mais diversas escalas, assim como, nas transformações socioeconômicos que ocorrem num ritmo cada vez mais acelerado.

Todavia, de forma geral, o processo de projetação de ambientes, assim como, de produtos assume uma estrutura que sugere etapas compostas por abordagens analíticas e normativas independente da demanda a ser atendida. Assim, surge modelos cujos métodos, técnicas e ferramentas que os compõem, estão sujeitos a variações, porém, diretamente atrelados as etapas semelhantes e aplicáveis a qualquer situação de projeto. O "processo de Design para fins didáticos, pode ser dividido em quatro fases distintas". (LÖBACH, 2001, p.141). De acordo com o autor, as fases de projeto nunca ocorrem separadas de fato, na realidade elas dialogam entre si com avanços e retrocessos dependendo da dinâmica encontrada em cada projeto e de maneira geral, as classifica da seguinte forma:

Fase 1 - Análise do problema - A descoberta de um problema constitui o ponto de partida e motivação para o processo do projeto, com a coleta e análises de dados do problema.

Fase 2 - Geração de alternativas - Após a primeira fase do processo de que se concentra na coleta e análises de dados pertinentes a cada produto a ser desenvolvido, o autor sugere a segunda etapa, em que são geradas as alternativas, processo criativo. 


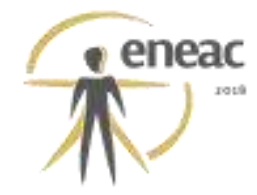

Fase 3 - Avaliação das alternativas - Neste momento, o autor propõe o exame das soluções e seu processo de seleção, ocorre também a comparação entre as alternativas apresentadas e os critérios elaborados previamente.

Fase 4 - Realização da solução do problema - o ultimo passo consiste na materialização da alternativa escolhida, que nem sempre é uma só alternativa isolada, mas o conjunto de boas características encontradas nas alternativas apresentadas.

Löbach (2001) também traz uma importante contribuição quando coloca que para o cumprimento de um bom processo de projeto, é importante dar atenção para as três funções que darão os atributos para a solução do problema, o que de certa forma, propõem para as pessoas envolvidas no desenvolvimento de projetos, um olhar mais cuidadoso às características físicas e cognitivas dos futuros usuários, são elas:

1) A função prática, que diz respeito a todas as relações entre o produto e seus usuários que se situam no nível orgânico - corporal. "São as funções de todos os aspectos fisiológicos do uso" (LÖBACH, 2001, p.58.).

2) Função estética, que se configura na relação entre o usuário e um produto no nível dos processos sensoriais. "A função estética dos produtos é um aspecto psicológico da percepção sensorial durante seu uso". Assim, criar função estética do produto, "significa configurar os produtos de acordo com as condições perceptivas do homem". (LÖBACH, 2001, p.59).

3) A função simbólica, que ocorre quando o homem percebe produtos ao estabelecer ligações com experiências e sensações já vividas. A "função simbólica dos produtos é determinada por todos os aspectos espirituais, psíquicos e sociais do uso". (LÖBACH, 2001, p, 64.).

Contudo, nos últimos anos, houve um aumento de novas abordagens de métodos de projeto com características inovadoras e uma quantidade significativa de novas técnicas e ferramentas de apoio ao desenvolvimento de projetos para as mais distintas abordagens, escalas e complexidade. Atualmente, ocorre notadamente um retorno aos temas de orientação social e "mais recentemente o foco das discussões passaram a ser o usuário, centrando o projeto na perspectiva das interfaces". (MALLIN, 2003.p.138). E neste contexto, cabe destacar que "o tema projeto centrado no usuário, se relaciona diretamente com a usabilidade”. (MERINO, 2014. p.44).

Com o mundo cada vez mais globalizado, os projetos de forma geral estão cada vez mais complexos com dinâmicas aceleradas a serem atendidas, se antes os projetos de produtos e ambientes construídos eram voltados para públicos de determinados segmentos da população e regiões, hoje arquitetos e designers devem pensar na possibilidade de atender uma diversidade maior de demandas e características de usuários em constante alteração. Para lida (2005) esse tipo de preocupação levou à formulação de critérios para melhorar a usabilidade dos produtos. Os critérios de usabilidade, de acordo com lida (2015), possuem uma semelhança com os universais, sendo a usabilidade voltada para facilitar o uso de produtos, sistemas e serviços e os universais para assegurar o uso ao maior número de pessoas possíveis aos ambientes, produtos e serviços.

A "usabilidade é o ponto até o qual o produto pode ser utilizado por usuários para alcançar objetivos específicos com eficácia, eficiência e satisfação em um contexto de uso específico "(ISO-9241-11).

Apesar muitos métodos de avaliação de usabilidade estarem diretamente associados a interfaces humano-computador e geralmente não são empregados para o desenvolvimento de ambiente construído e produtos, Jordan (1998) apresenta dez princípios de usabilidade considerados necessários para nortear o processo de design (projeto), sendo eles: consistência, que está relacionado com tarefas similares que devem ser executadas em 


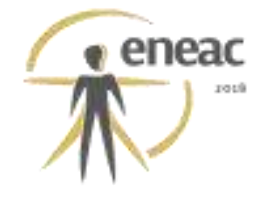

modos similares. Compatibilidade, projetar com compatibilidade significa se certificar de que a função do produto está ligada à expectativa do usuário baseado em seus conhecimentos. Feedback, consiste em desenvolver interfaces que forneçam respostas claras sobre qualquer ação que o usuário desenvolva. Clareza visual, é importante que as informações sejam apresentadas de tal maneira que possa ser interpretada rápida e facilmente, sem causar qualquer confusão. Clareza de operação, está relacionada com o desenvolvimento de produtos e sistemas com modo claro de como operá-los. Controle pelo usuário, os produtos devem ser projetados de modo a dar aos usuários controle sobre as interações possíveis. Prevenção e recuperação de erros, produtos podem ser projetados de maneira que se as possibilidades de erros acontecerem, sejam minimizadas e que os usuários possam se recuperar rapidamente e facilmente de qualquer erro que comentam. Consideração de recursos do usuário, é importante que quando se interage com um produto ou sistema, nenhum canal sensorial do usuário seja sobrecarregado. Apropriada transferência de tecnologia e prioridade da funcionalidade e informação, consiste em aplicar tecnologias que foram desenvolvidas para um propósito a uma nova área no sentido de trazer novos benefícios aos usuários.

Para Cambiaghi (2007) "a usabilidade trata da adequação entre o produto, as tarefas a cujo desempenho ele se destina e o usuário que o utilizará". (CAMBIAGHI, 2007, p.42). Ela depende "da interação entre produto, o usuário, a tarefa e o ambiente" (IIDA,2005. p.321).

Enfim, diante do cenário de complexidade que atualmente vivemos onde o fluxo de informações é extremamente abundante, o papel da arquitetura e do design, talvez seja o de "reinserir os valores humanos e da sensibilidade humana no mundo material, para fazer nossas interações com o produto menos impessoais e estritamente funcionais, e mais relacionais, agradáveis e confiáveis" (NIEMEYER, p. 52).

\subsection{Considerações sobre projeto centrado no usuário}

O desenvolvimento de projeto centrado no usuário "implica descobrir muitas coisas sobre os mesmos e suas tarefas e utilizar essas informações para alimentar o design". (PREECE, ROGER e, SHARP, 2005, p.299). Uma forte característica desta abordagem de projeto, consiste na possibilidade de trazer o futuro usuário ou grupo de usuários, como agente ativo no processo de desenvolvimento de projetos já nas fases iniciais, e assim, proporcionar o surgimento de informações importantes a respeito das suas necessidades e objetivos.

Neste contexto cabe a colocação de De Moraes (2010) ao comentar que a forma do produto não se apresenta mais como uma questão objetiva funcional, mas está sim ligada a fatores semânticos, psicológicos e subjetivos.

Harada et al. (2016), coloca que,

o Design Centrado no Usuário (DCU) leva em consideração aspectos sociais, físicos e cognitivos do seu público, e utiliza uma abordagem que não impõe suas preferências e soluções. Contrariamente, imprime e traduz a vontade do público além de estimula-lo a compreender suas próprias necessidades através da solução final do projeto. (HARADA et al.2016, p.92).

Contudo, torna-se importante para o processo de projeto centrado no usuário, o envolvimento de usuários reais, dessa forma é possível por parte dos profissionais envolvidos, uma proximidade maior com a identificação dos atributos importantes e necessários ao produto ou ambiente que está sendo projetado, frente às expectativas dos futuros usuários. Dessa forma, os projetos passam a ser elaborados a partir dos usuários. 


\section{(inser}

\section{CONSIDERAÇÕES FINAIS}

Os estudos desenvolvidos até o momento apontam para a possibilidade de se relacionar o conhecimento dos processos sensoriais descritos (GIBSON,1966), sobretudo, para a aplicação em fases inicias de projetação (estruturação de requisitos, geração e refinamento de alternativas) com os 10 (dez) princípios de usabilidade, proposto principalmente por (JORDAN,1998), somado aos 7 (sete) princípios do Desenho Universal (DU) desenvolvidos pelos pesquisadores do Centro de Design Universal da Universidade da Carolina do Norte/EUA.

Questões, por exemplo, relacionadas com Sistema Básico de Orientação descrito por Gibson (1966), responsável pelo equilíbrio do corpo e orientação respondendo às forças de gravidade e aceleração, que podem ser trabalhadas ao serem relacionadas a critérios de usabilidade (JORDAN,1998), como a Compatibilidade, que se configura em projetar um produto de modo que seu método de operação seja compatível com as expectativas baseadas no conhecimento de outros tipos de produtos e experiências de uso no mundo. Da mesma forma, podem simultaneamente ser associados a Princípios Universais como por exemplo, Uso Simples e Intuitivo que consiste na fácil compreensão de produtos e sistemas, independentemente da experiência, conhecimento, das capacidades linguísticas ou do nível de concentração do usuário.

Nesta perspectiva, cabe esforços para a criação de recursos de projetação, que sejam capazes de contribuir com o incremento de informações para arquitetos e designers durante o desenvolvimento do ambiente construído e produtos diversos, sobretudo no sentido de trazer reflexões sobre a possibilidade de experimentar novos caminhos para materializar conceitos, requisitos e alternativas de propostas baseados nos conhecimentos dos sistemas sensoriais, articulados com os conceitos apresentados neste artigo.

\section{REFERÊNCIAS BIBLIOGRÁFICAS}

ASSOCIAÇÃO BRASILEIRA DE NORMAS TÉCNICAS - ABNT. NBR 9050: Acessibilidade a edificações, mobiliário, espaços e equipamentos urbanos. Rio de Janeiro, 2015.149 p.

BINS ELY, Vera H. M. Orientar-se no espaço: condição indispensável para a acessibilidade. In: SEMINÁRIO NACIONAL ACESSIBILIDADE NO COTIDIANO, 1, 2004, Rio de janeiro. Anais...Rio de Janeiro: UFRJ, 2004.

BOMFIM, Gustavo Amarante. Metodologia para desenvolvimento de projetos. João Pessoa: Editora Universitária/UFPB, 1995. 69 p.

BONSIEPE, Gui. Design como prática de projeto. São Paulo:Blucher, 2012.

CAMBIACHI, Silvana. Desenho universal: método e técnicas para arquitetos e urbanistas. São Paulo: SENAC São Paulo, 2007.269p.

CASTILLO, Y. Criterios de diseño polisensorial aplicables en la arquitectura habitacional en la ciudad de Loja. 2009. Tese (Doutorado.) - Universidade de Loja, Ecuador, 2009.

CHAUÍ, Marilena. Convite à filosofia. São Paulo:Ática,1995.

CARLIN, Fernanda. Acessibilidade espacial em Shopping Centers: um estudo de caso. 2004. Dissertação (Mestrado) - Universidade Federal de Santa Catarina, Programa de Pós- Graduação em Engenharia de Produção. Florianópolis, 2004. 191 p.

CRUZ, Vanessa Carla Duarte Santos. Design inclusivo: projeto para o desenvolvimento de uma ajuda técnica numa perspectiva de design inclusivo. 2010. 170 f. Dissertação (Mestrado) - 


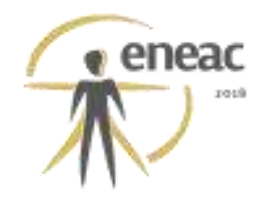

Departamento de Engenharia Eletromecânica, Universidade da Beira Interior, Covilhã - Portugal, 2010.

DISCHINGER, M. Design for all senses: accessible spaces for visually impaired citizens. Goteborg, Swenden. 2000.260p. Theses (for the degree of Doctor of Philosophy)- Departamento f Space and Process School of Architeture, Chalmers University of Tecnology, 2000.

FRANCO, Sérgio A. S. Gestão e Design Universal. Design Inclusive, Cadernos de Design Anuário, Centro Português de Design, Lisboa, ano 9, n. 23/24, p. 86-87, 2001.

GIBSON, James J. The Senses Consedered as Perceptual Systems. Boston: Houghtan Miffin Company, 1966.

GEHL, Jan, 1936-Cidades Para Pessoas/Jan Gehl; tradução Anita Di marco.-1. ed-São Paulo:Perspectiva,2013.

GRANDEJEAN, Etiene. Manual de ergonomia: adaptando o trabalho ao homem. Porto Alegre: Artes Médicas, 1998. 338 p.

HARADA, F. J. B.; CHAVES, I. G.; CROLIUS, W. A.; FLETCHER, V.; SCHOR, P. O Design Centrado

No Humano Aplicado: A utilização da abordagem em diferentes projetos e etapas do design. Revista D.: Design, Educação, Sociedade e Sustentabilidade, Porto Alegre, v.8 n.2, 87-107, 2016.

IIDA, Itiro. Ergonomia: Projeto e Produção. Rio de Janeiro: Edgard Blücher, 2000 (6ª reimpressão). $614 p$. Ergonomia e projeto.

JORDAN, Patrick. An introduction to usability. London: Taylor \& Francis, 1998.

LÖBACH, Bernd. Design industrial: bases para a configuração dos produtos industriais. São Paulo: Edgard Blücher, 2001. 206 p.

MARLIM, Sandra Sueli Vieira. Uma metodologia de design aplicada ao desenvolvimento de Tecnologia Assistiva para portadores de Paralisia Cerebral. Curitiba: Editora da UFPR, 2004. $220 \mathrm{p}$.

MERINO, Giselle Schmidt Alves Díaz. METOdOLOGIA PARA A PRÁTICA PROJETUAL DO

DESIGN com base no Projeto Centrado no Usuário e com ênfase no Design Universal, Tese submetida ao Programa de Pós-Graduação em Engenharia de Produção da Universidade Federal de Santa Catarina.

NIEMEYER, Lucy. Design Atitudinal: uma abordagem projetual. Design, ergonomia e emoção. Organização Claudia Mont'Álvão e Vera damazio. - Rio de janeiro: Mauad X:FAPERJ, 2008. pp. 4964.

PALLASMAA, Juhaní, Os olhos da pele: a arquitetura e os sentidos/Juhaní Pallasmaa; tradução técnica: Alexandre Salvaterra, - Porto Alegre: Bookman, 2011, 76p.

PREECE, Jeniffer; ROGERS, Yvonne; SHARP, Helen. Design de interação: além da interação homem-computador. Porto Alegre: Bookman, 2005.

MARTINS, Rosane Fonseca; LIN, Julio Carlos de Souza Van Der. Pelos caminhos do Design: metodologia de projeto. Londrina: Eduel, 2012c. p. 297-325.

PAIVA, Rodrigo Balestra Ferreira de. Design e emoção: conceitos fundamentais. Ensaios sobre Design, Cultura e Tecnologia. Design, Artefatos e Sistema Sustentável. Organizadores, Amilton J. V. Arruda Paulo Cesar Machado Ferroli Lisiane Ilha Liberlotto.Blucher. pp.12-34. 


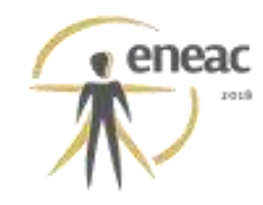

SANTOS, Milton. Espaço e método. São Paulo: Nobel, 1985.

SEVCENKO, Nicolau. A corrida para o século XXI: no loop da montanha - russa. São Paulo: Companhia das Letras, $2001.140 \mathrm{p}$.

SIMÕES, Jorge Falcato, BISPO, Renato. Design Inclusivo: acessibilidade e usabilidade em produtos, serviços e ambientes. Manual de apoio às ações de formação do projeto de Design Inclusivo. 2. ed. Lisboa: Centro Português de Design, 2006. 70p.

TUAN, Yi-fu. Traços comuns em percepção dos sentidos. In: Topofilia: um estudo de percepção, atitudes e valores do meio ambiente. Tradução Lívia de Oliveira. São paulo: Dlfel, 1980.p. 6-14. 